\title{
Problemas actuales sobre la interpretación constitucional de los derechos*
}

\author{
Current problems with the Constitutional \\ interpretation of rights
}

\section{Rubén Martínez Dalmau**}

\section{RESUMEN}

Este trabajo tiene por objeto establecer cuatro cuestiones esenciales sobre la interpretación de los derechos constitucionales. Éstos deben seguir siendo objeto de estudio por parte de la doctrina, pues los avances, hasta el momento, han sido relevantes, pero no concluyentes. La primera de estas cuestiones es qué implica la interpretación de los derechos y cuál es la problemática que la envuelve; la segunda, qué mecanismos de solución de conflictos de derechos pueden ser los más adecuados en el marco de una Constitución democrática; la tercera, cuál es la diferencia entre la función de la justicia ordinaria y de la justicia constitucional; $y$, por último, qué diferencia existe entre la supremacía constitucional y la aplicación preferente de los derechos prevista en el derecho internacional o el derecho de integración, así como en determinadas Constituciones.

PALABRAS CLAVE: Interpretación constitucional, derechos, constitucionalismo democrático, justicia constitucional, ponderación.

\begin{abstract}
The aim of this paper is to establish four essential questions on the interpretation of the constitutional rights that should continue to be an object of study relative to the doctrine as the progress to date, although relevant, has not been conclusive. In the first place, what involves the interpretation of rights and what is the problem that surrounds it. Secondly, what mechanisms of conflict resolution of rights could be the most suitable in the frame of a democratic constitution constitution. Thirdly, what is the difference between the role of the usual justice system and constitutional justice. Finally, what is the difference between constitutional supremacy and the preferred application of rights provided in international law or in integration law, as well as in certain Constitutions.
\end{abstract}

KEY WORDS: Constitutional Interpretation, rights, democratic constitutionalism, constitutional justice, weighting.

\footnotetext{
* Recibido: 14 de agosto de 2015. Aprobado: 26 de septiembre de 2015.

** Profesor titular de Derecho Constitucional en la Universidad de Valencia, España. (ruben.martinez@uv.es)
} 


\section{SUMARIO}

1. Introducción

2. La interpretación constitucional de los derechos

3. Conflictos de derechos, ponderación y proporcionalidad

4. El concepto de juez constitucional y el debate sobre la posible contradicción entre principios y reglas

5. Derechos constitucionales, derecho internacional y derecho de la integración

6. Conclusiones

\section{Introducción}

Uno de los retos del constitucionalismo democrático, en la actualidad, es su aplicación efectiva. Históricamente, la aplicación constitucional, en particular de la parte dogmática de la Constitución, ha sido la más problemática por varias razones. En primer lugar, la garantía de los derechos constitucionales cuenta con una gran carga emancipadora y, por ello, suele producir resistencias y dificultades en su aplicación material. En segundo lugar, los derechos constitucionales suelen estar formulados como principios, por lo cual, técnicamente, ha contado con menos facilidades para su aplicación que las normas orgánicas, generalmente formuladas como reglas. Respecto a la aplicación de las reglas, la problemática es menor por sus posibilidades cerradas; respecto a los derechos formulados como principios, por su naturaleza abierta, la ciencia del derecho constitucional sigue preguntándose cuál es la mejor forma de garantizar su aplicación. ${ }^{1}$

Las últimas décadas han sido protagonistas de un fulgurante interés por la interpretación constitucional, donde han intervenido autores desde las más diferentes perspectivas de las ciencias sociales, principalmente la filosofía del derecho y el derecho constitucional. La recuperación de la normatividad constitucional, la necesidad de encontrar nuevas vías para la aplicación de la Constitución, y el cambio de paradigma desde el Estado legal al Estado constitucional se conforman como razones de gran peso a la hora de explicar esta no nueva, pero sí transformada voluntad de estudiar la interpretación constitucional. En particular, ha sido necesario revisar la relación entre interpretación constitucional y aplicación de la Constitución en esta parte constitucional más

\footnotetext{
${ }_{1}^{1}$ Para la elaboración del presente trabajo se ha partido de las reflexiones realizadas por el autor en Cuatro preguntas sobre la interpretación constitucional de los derechos en el Estado constitucional, publicado por la Universidad Libre de Colombia, Bogotá, 2016.
} 
transformadora e históricamente relegada: la parte dogmática, que determina y garantiza los derechos constitucionales. ${ }^{2}$

Autores de diferentes sistemas jurídicos, latitudes y concepciones ideológicas han suscitado varias cuestiones. De ellas, hemos elegido cuatro que perfilan la problemática actual sobre la interpretación de los derechos: ${ }^{3}$ 1) Qué implica la interpretación constitucional de los derechos; 2) Cuál es el papel de la interpretación constitucional para encontrar solución a los conflictos de derechos; 3) Cuál es la función del juez ordinario y del juez constitucional en la garantía de los derechos; 4) Cómo se soluciona el problema de la interpretación de los derechos protegidos constitucionalmente en el marco de los procesos de integración.

El presente trabajo tiene por objeto realizar una aproximación a estas cuestiones y aportar, con ello, posibles soluciones a la reflexión colectiva sobre la función de la interpretación constitucional en la aplicación de los derechos.

\section{La interpretación constitucional de los derechos}

La primera pregunta que cabe realizar sobre la interpretación constitucional de los derechos es: ¿qué implica interpretar los derechos constitucionales? Ésta nos llevaría a establecer si realmente existe una interpretación constitucional de los derechos, no sólo formalmente, sino sustantivamente distinta a la interpretación legal. Parece obvia la respuesta, pero no lo es. En nuestro caso, hemos defendido la especificidad de la interpretación constitucional en relación con los derechos y la Constitución, partiendo del concepto de Constitución democrática. Esto es, aquella cuya voluntad del poder constituyente, creador de la Constitución, es diferente a la del poder constituido, atrapado y limitado en la Constitución y por la Constitución. Convenimos así que no existe norma jerárquica superior a la Constitución democrática, la única originaria del poder constituyente democrático. Por lo tanto, el problema no es propiamente diferenciar entre interpretación constitucional e interpretación legal, sino entre interpretación

\footnotetext{
${ }^{2}$ Algunas de estas preocupaciones se tomaron en cuenta en MARtinez Dalmau, Rubén. "La interpretación de la Constitución democrática", en AA.W., Costituzione, Economia, Globalizzazione. Liber Amicorum in Onore di Carlo Amirante, Edizioni Schientifiche Italiane, Nápoles, 2013.

${ }^{3}$ En este sentido, véase HäBERLE, Peter. "La sociedad abierta de los intérpretes constitucionales: una contribución para la interpretación pluralista y procesal de la Constitución", en Academia. Revista sobre la Enseñanza del Derecho, No. 11, 2008, p. 47; Pozzolo, Susana. "Neoconstitucionalismo y especificidad de la interpretación constitucional", en Doxa, No. 21, año II, 1998, pp. 347 y ss; Prieto Sanchis, Luis. "Notas sobre la interpretación constitucional", en Revista del Centro de Estudios Constitucionales, No. 9, mayo-agosto de 1991, p. 177; y De Montalvo JäÄskelïnen, Federico. "La interpretación constitucional: problemas de método y de intérprete", en Icade. Revista cuatrimestral de las Facultades de Derecho y ciencias económicas y empresariales, No. 82, enero-abril 2011, p. 59.
} 
de la Constitución democrática y aquélla que no lo es. Donde, por lo tanto, no se distingue entre voluntad del poder constituyente democrático y voluntad del poder constituido. ${ }^{4}$

Aunque la diferencia entre interpretación legal e interpretación constitucional ya es de por sí compleja, se puede complicar aún más si abundamos en la pregunta: ¿existen artículos constitucionales de una categoría diferente a la de otros? Sin duda, el problema nos recordará a Bachof y a la tentadora, pero difícilmente justificable, teoría sobre la posibilidad de normas constitucionales inconstitucionales. ${ }^{5}$ Pero, más recientemente, una parte de la doctrina se ha esforzado en definir esta diferenciación en relación con el concepto de Estado constitucional. Lo ha hecho observándolo desde el prisma de la distinción sustantiva, propia de los derechos que deben estar recogidos y protegidos en un Estado constitucional. Un Estado constitucional, afırma Aguiló, no sería sólo aquél que cuenta con una Constitución entendida como lex superior, sino con una Constitución con un contenido sustantivo propio del Estado constitucional. En buena parte, este contenido son derechos. "En toda Constitución del Estado constitucional hay normas y principios necesarios. No es concebible un Estado constitucional sin derecho a la libertad de expresión, sin derecho de asociación, sin democracia o sin los principios de independencia e imparcialidad de los jueces, etc. Sin esos derechos y/o principios habrá lex superior, pero no Estado constitucional de derecho". ${ }^{6}$

\footnotetext{
${ }^{4}$ Ibid. p. 439.

${ }^{5}$ Recordemos que la arriesgada propuesta de Bachof realizada en la conferencia en la Universidad de Heidelberg en 1951 tuvo como principal objetivo evitar actuaciones extralimitadas del poder legislativo como la aprobación en Alemania de la Ley de plenos poderes, que suprimió de manera definitiva la Constitución de Weimar. Bachof propuso fortalecer la competencia del Tribunal Constitucional para decidir sobre la posibilidad de normas formalmente constitucionales pero materialmente inconstitucionales. Aduce para ello la existencia de cláusulas de intangibilidad en la Ley Fundamental de Bonn. "Un análisis de las correspondientes normas de la Constitución [...] hace suponer que el constituyente ha entendido por examinar la 'constitucionalidad' de las normas, ante todo, aunque no de manera exclusiva, constatar si las normas inferiores a la Constitución -que opera como parámetro- resultan compatibles con las normas constitucionales. Ya sea el examen de la compatibilidad de las simples leyes de los Estados federados a sus propias Constituciones, ya sea el examen de la compatibilidad del derecho de los Estados federados (incluido el derecho constitucional de dichos Estados) y de las leyes del Estado federal con la Constitución federal. Sin embargo, también es pensable una 'inconstitucionalidad' de las normas constitucionales (ubicadas en un mismo plano), que tampoco puede ser excluida de control jurisdiccional. Eso es lo que se deriva del hecho de que la Constitución [...] declare intangibles algunas de sus normas". ВАСНОF, Отто. ¿Normas constitucionales inconstitucionales? Palestra, Lima, 2010, p. 28.

Los problemas de seguridad jurídica y la necesidad de comprender la posibilidad de excepciones a normas generales han decantado la preferencia en los sistemas comparados de control de la constitucionalidad hacia el control de constitucionalidad de los actos de reforma, por lo cual, la propuesta de Bachof, enmarcada en un contexto histórico particular después de la experiencia nazi y la Segunda Guerra Mundial, no ha sido generalmente acogida. Al respecto, cfr. Martinez Dalmau, Rubén. "La interpretación...", op. cit., p. 441.

${ }^{6}$ Agultó Regla, Josep. "Interpretación constitucional. Algunas alternativas teóricas y una propuesta", en Doxa, Cuadernos de Filosofía del Derecho, No. 35, 2012, p. 254.
} 
El gran problema de las tesis sobre la diferenciación de normas entre lo que podríamos denominar sustantivas (o propias del Estado constitucional; necesarias, en términos de Aguiló) y adjetivas (contingentes o idiosincrásicas, en términos de Aguiló) es que cuenta con la misma naturaleza que en el caso del debate entre iusnaturalismo e iuspositivismo. Su determinación es finalmente subjetiva, aunque busque en el derecho constitucional común su objetivación. Pero la decisión sobre qué normas son sustantivas y cuáles adjetivas sólo puede fundamentarse en criterios subjetivos determinados.

Como afirma Aguiló, el hecho de que sean expresión de un consenso ideal más que de una autoridad ("nadie acude a la noción de poder constituyente para explicar por qué esos principios forman parte de la Constitución”), ${ }^{7}$ no elude el hecho de que en el campo de la facticidad sí son fruto de un poder constituyente. Además, la determinación sobre qué derechos son propios del Estado constitucional y cuáles no, entendidos desde la posición del consenso ideal o del derecho común, es una construcción posterior a la manifestación de esas voluntades, necesariamente subjetiva.

De hecho, la voluntad del poder constituyente que determina los derechos es justamente la que los dota de objetividad al crearlos y garantizarlos. El propio Aguiló parece apuntar el problema cuando afirma que "es discutible cuál es el contenido esencial del Estado constitucional (aquel sin el cual no podría hablarse de Estado constitucional)", ${ }^{8}$ y el hecho de que sea discutible hace más débil el argumento.

Siguiendo con la pregunta ¿qué implica interpretar los derechos constitucionales?, cabe hacer mención a la naturaleza de la función de interpretación. Aunque con aristas diferentes, una de las particulares problemáticas de la interpretación de la Constitución en general, y de los derechos en particular, es el auge obtenido durante las últimas décadas. Éste se dio entre determinada doctrina, la interpretación evolutiva, dinámica o habitualmente conocida como interpretación del "árbol vivo", con raíces claramente dworkinianas, aunque no exclusivamente. Podríamos definir con Guastini la doctrina evolutiva como aquella inspirada en la necesidad de adaptación continua del derecho a las exigencias de la vida social (política, económica, etcétera). Por ello, esta doctrina sugiere a los intérpretes no practicar una interpretación fija sino, por el contrario, cambiar el significado del texto a la luz de las circunstancias y a la luz de sus sentimientos de justicia. ${ }^{9}$

\footnotetext{
${ }^{7}$ lbid. p. 255.

${ }^{8}$ Ibid. p. 254.

${ }^{9}$ Guastini, Riccardo. Teoría e ideología de la interpretación constitucional, Trotta, Madrid, 2008, p. 61, que cita directamente fuentes de Dworkin. Se contrapondría de esta manera a la que Guastini denomina doctrina estática,
} 
Las doctrinas de la interpretación evolutiva cuentan con un denominador común basado en tres premisas: 1) en la Constitución cabe más de una interpretación posible, a causa de la textura abierta de los postulados constitucionales; 2) la rigidez constitucional paraliza la evolución del ordenamiento constitucional; 3) corresponde al juez romper con esta esclerosis del texto constitucional a través del descubrimiento de nuevos significados en el marco de la textura abierta de la Constitución. Este activismo judicial se traduciría siempre en una interpretación evolutiva que acercaría la relación entre norma constitucional y realidad social. Un defensor de la interpretación evolutiva como Canosa no lo podría resumir mejor: "Tanto más necesario será utilizar el elemento evolutivo cuanto más parezca a priori que el enunciado normativo se aleja de la realidad [...]. La interpretación evolutiva supone, como vemos, una elección del intérprete: optar entre la interpretación anteriormente dada a una disposición pero que ya no permite someter la realidad, o extraer otra nueva que sirva a ese propósito". ${ }^{10}$ De hecho, las teorías del árbol vivo plantean una diferenciación sustancial entre el juez como mera boca de la ley, que sería propio del Estado legal, y el juez intérprete evolutivo que se requeriría en la actualidad:

Esta posibilidad -continúa Canosa- de elegir entre mantener el sentido tradicional o desvelar otro hasta entonces oculto, presupone un intérprete creador, alejado del modelo de juez ventrílocuo que imperó durante tanto tiempo [...]. Al interpretar en clave evolutiva, el juez no puede expresar esta voluntas legislatoris que no pudo prever cómo la realidad futura evolucionaría, sino que, constreñido por esos cambios, ha de hallar, en el enunciado normativo, un sentido, una norma concreta, que permita a la disposición seguir siendo eficaz. ${ }^{11}$

Es sus posturas más moderadas, las doctrinas de la interpretación evolutiva reconocen las limitaciones del árbol vivo: el propio tenor textual de la ley. Es decir, plantean la posibilidad de interpretación desde la textualidad de la norma,

inspirada en los valores de estabilidad de la disciplina jurídica, de la certeza del derecho, y de la previsibilidad de las decisiones jurisdiccionales. Por eso esta doctrina recomienda a los intérpretes practicar una interpretación estable, fija, diacrónicamente constante, sin revirements (p. 60).

${ }^{10}$ CAnosa Usera, Raúl. "Interpretación evolutiva de los derechos fundamentales", en Ferrer Mac-Gregor, Eduardo y Zaldivar Lelo de Larrea, Arturo (Coords.), La ciencia del Derecho procesal constitucional. Estudios en homenaje a Héctor Fix-Zamudio en sus cincuenta años como investigador del Derecho, tomo VI, Interpretación constitucional y jurisdicción electoral, Instituto de Investigaciones Jurídicas - Universidad Nacional Autónoma de México, México, 2008, pp. 59-60.

${ }^{11}$ Ibid. p. 60. 
sin que quepa interpretación contra legem, la cual convertiría al intérprete en un sustituto del constituyente. En términos también de Canosa:

la interpretación evolutiva es sólo posible cuando el enunciado normativo permite derivar de él varios sentidos posibles de los que el intérprete escoge el que mejor asegure su eficacia [...]. Es verdad que la literalidad del precepto y su finalidad le constriñen y no puede extraer de las palabras de la disposición un significado incompatible con ellas ni tampoco puede pervertir la finalidad de la disposición ni sacarla de su contexto normativo. ${ }^{12}$

La textura abierta, como bien demuestra Guastini, es reducible, aunque inevitable. ${ }^{13}$ Pero referirnos a la interpretación evolutiva nos lleva necesariamente a un segundo problema: ¿qué entendemos por evolución? ¿La interpretación necesariamente subjetiva sobre lo que es evolutivo y lo que no lo es? (Con independencia de que el juez busque argumentos objetivos como sondeos o encuestas de opinión). ${ }^{14}$ Cabe ser honestos con el objetivo del juez en la interpretación evolutiva: no es sólo fortalecer la relación entre normatividad y realidad, y huir de esta manera del nominalismo constitucional. También es transformar la realidad social a través del cambio en el significado de las disposiciones constitucionales. En este ámbito, el intérprete evolutivo se mueve en aguas cenagosas, puesto que un exceso en la función interpretativa podría acabar en la sustitución de la voluntad constituyente, por la voluntad del juez como intérprete evolutivo. Pondría con ello en peligro la legitimidad democrática de la Constitución y, por lo tanto, del resto del ordenamiento jurídico,

\footnotetext{
12 Ibid. p. 59.

${ }^{13}$ GuastinI, Riccardo. Op. cit. p. 30.

${ }^{14}$ Como es el caso, por ejemplo, de la fundamentación de la sentencia del Tribunal Constitucional español 198/2012, de 6 de noviembre, que declara la constitucionalidad de la reforma del artículo 44 Código Civil que legaliza el matrimonio entre personas del mismo sexo, interpretando el derecho a contraer matrimonio consagrado en el artículo 32 de la Constitución española de 1978. El Fundamento Jurídico 9 afirma que "este Tribunal no puede permanecer ajeno a la realidad social y hoy existen datos cuantitativos contenidos en estadisticas oficiales, que confirman que en España existe una amplia aceptación social del matrimonio entre parejas del mismo sexo, al tiempo que estas parejas han ejercitado su derecho a contraer matrimonio desde el año 2005. Respecto a la opinión que merece a los españoles la existencia del matrimonio entre personas del mismo sexo, el Centro de Investigaciones Sociológicas, con motivo de la elaboración del anteproyecto de ley por la cual se modifica el Código civil en materia de derecho a contraer matrimonio, incluyó la cuestión en diversas encuestas. En el barómetro de junio de 2004 (estudio núm. 2.568), se refleja que $66.2 \%$ de los encuestados creia que las parejas homosexuales debian tener derecho a contraer matrimonio, mientras que en el estudio relativo a 'opiniones y actitudes sobre la familia' (núm. 2578) realizado durante los meses de octubre y noviembre de 2004, se recoge que el 56,9\% de los encuestados estaban a favor de permitir el matrimonio civil para las parejas del mismo sexo". Tras lo cual el Tribunal hace constar toda una serie de datos estadísticos comparados con el objetivo de sustentar complementariamente la decisión.
} 
cuya legitimidad proviene de ésta. Por esa razón, la interpretación evolutiva no sólo está limitada por el tenor literal del texto y por las condiciones de normatividad de la disposición, sino que debe tomar en cuenta la voluntad del poder constituyente democrático. Éste es quien determinó la existencia de las normas constitucionales, objeto de interpretación a través de un debate público, democrático, capaz de producir voluntad general. Es, en definitiva, quien legitimó la Constitución. ${ }^{15}$

En caso de que la adaptación social y la normatividad de la disposición fueran tan relevantes como para considerar un significado contrario a la voluntad del constituyente, una Constitución democrática no debería tener obstáculos para ser modificada democráticamente, a través de una nueva generación de voluntad general: debate público y decisión colectiva sobre la disposición correspondiente.

El carácter emancipador de la Constitución democrática requiere de esta potencial revisión, que rompería formalmente la rigidez justificadora de la decisión judicial evolutiva. Así podría o no coincidir con la decisión democrática; ésta decisión sería la evolutiva. Hurtar la decisión al debate público y hacerla recaer sobre los hombros del juez haría un flaco favor a la evolución democrática de la sociedad a través de la dialéctica constituyente que soluciona de manera emancipadora la tensión entre democracia y constitucionalismo. ${ }^{16}$

\section{Conflictos de derechos, ponderación y proporcionalidad}

La segunda de las preguntas que nos hemos formulado es: ¿cómo puede servirnos la interpretación constitucional para encontrar solución a los conflictos de derechos? El conflicto de derechos en el marco de la Constitución ha sido una de las preocupaciones principales del derecho constitucional, a partir de la recuperación de la normatividad constitucional. Prácticamente, todos los teóricos clásicos sobre derechos constitucionales han tratado prominentemente esta cuestión. Ésta se relaciona directamente con los límites 136 de los derechos, a partir de la premisa de que la efectividad de los derechos supone comprender que ninguno de ellos es absoluto, si ello pone en juego la efectividad de otros derechos. Esto último implica aceptar la existencia de limites y de conflictos. ${ }^{17}$

\footnotetext{
${ }^{15}$ Al respecto, cfr. Martinez Dalmau, Rubén. "La interpretación...", op. cit. p. 442.

${ }^{16}$ Respecto a la dialéctica constituyente, cfr. Martinez Dalmau, Rubén. "El debate sobre la naturaleza del poder constituyente: elementos para una teoria de la Constitución democrática", en Martínez Dalmau, Rubén (Ed.), Teoría y práctica del poder constituyente, Tirant, Valencia, 2014, p. 101.

${ }^{17}$ Cfr. Peces-Barba Martinez, Gregorio. Escritos sobre derechos fundamentales, Eudema, Madrid, 1988, p. 97.
} 
A partir de las doctrinas alemanas sobre el contenido esencial, fundadas en el conocido artículo 19.2 de la Ley Fundamental de Bonn, ${ }^{18}$ se construyó durante la segunda mitad del siglo xx un paradigma de solución de los conflictos entre derechos. Se basó en la protección por parte del legislador y del juez de los rasgos identitarios que configuran el derecho, así como en sus límites inmanentes, y sin cuya garantía no podríamos referirnos a un reconocimiento del derecho. ${ }^{19}$ Pero la doctrina del contenido esencial es una garantía formulada expresamente en relación con la ley. "Es decir, como operativo únicamente en el momento de normación o regulación del ejercicio de los derechos fundamentales". ${ }^{20}$

Durante las últimas décadas, a raíz de los estudios sobre la concepción de los derechos como principios, las teorias de la ponderación (balancing) han contado con un desarrollo extraordinario. Asimismo, estas teorías derivaron del pensamiento constitucional alemán y la doctrina del contenido esencial. ${ }^{21}$ El reconocimiento del conflicto de derechos y la necesidad de mejorar el proceso de argumentación han ocasionado que teóricos de todo el mundo, así como importantes tribunales con funciones de máxima interpretación de la Constitución, presten un interés inusitado a la ponderación como medio de efectividad de los derechos, por lo general estructurados constitucionalmente como principios. Los principios consiguen su máxima efectividad a través de la ponderación, frente a las reglas que requieren la aplicación del silogismo de la subsunción. En términos de Bernal:

en el mundo jurídico global se acepta cada día más la tesis de que los sistemas jurídicos modernos están compuestos por dos tipos básicos de normas: las reglas y los principios. Estos dos tipos de normas se aplican por medio de dos procedimientos diversos: la subsunción y la ponderación. Mientras las reglas se aplican por medio de la sub-

\footnotetext{
18 "En ningún caso se podrá afectar al contenido esencial de un derecho fundamental". El campo de influencia en el constitucionalismo comparado de esta garantia ha sido amplisimo; como ejemplo, valga citar el también conocido artículo 53.1 de la Constitución española: "Los derechos y libertades reconocidos [...] vinculan a todos los poderes públicos. Sólo por ley, que en todo caso deberá respetar su contenido esencial, podrá regularse el ejercicio de tales derechos y libertades [...]".

${ }^{19}$ La tesis doctoral de Peter Häberle, publicada en 1962, fue particularmente importante e influyente en ese asunto. Avanzó ampliamente hacia conceptos como el de Estado constitucional, Constitución abierta, dimensión institucional e individual de los derechos, el fundamento de los derechos en la salvaguarda de la dignidad y, por supuesto, el significado del contenido esencial. Cfr. HëBerLE, Peter. La garantía del contenido esencial de los derechos fundamentales en la Ley Fundamental de Bonn, Dykinson, Madrid, 2003.

${ }^{20}$ Parejo Alfonso, Luciano. "El contenido esencial de los derechos fundamentales en la jurisprudencia constitucional; a propósito de la sentencia del Tribunal Constitucional de 8 de abril de 1981", en Revista Española de Derecho Constitucional , No. 3, año I, septiembre-diciembre 1981, p. 182.

${ }^{21}$ El propio Häberle había analizado el problema de la ponderación de bienes frente a la relativización de los derechos en la segunda parte de La garantía..., op. cit.
} 
sunción, los principios se aplican mediante la ponderación. Por este motivo, la ponderación se ha convertido en un criterio metodológico básico para la aplicación jurídica, en especial, para la aplicación jurídica de los derechos fundamentales. ${ }^{22}$

La relación entre interpretación y ponderación es directa y se presupone, aunque estrictamente la ponderación esté al servicio de la categoría más general de interpretación. Como afirma Carpio, al analizar las relaciones entre interpretación y balancing, inmediatamente se observa que el uno presupone al otro, y viceversa. La interpretación, en efecto, recae sobre una disposición constitucional. La ponderación (actividad), en cambio, sobre intereses o bienes que esas disposiciones contienen. En un caso de colisión entre derechos fundamentales, habitualmente se parte de identificar los bienes o intereses en conflicto (balancing actividad); se realiza la interpretación de las disposiciones que los reconocen (interpretación); se advierten las circunstancias del caso y, luego, se procede a realizar el balanceamiento de los intereses, a fin de brindar una solución al caso (balancing producto). ${ }^{23}$ La piedra de toque para la realización efectiva de la ponderación sería el principio de proporcionalidad. ${ }^{24}$

Como afirma Alexy, ${ }^{25}$ hay dos posturas ante la conexión entre los derechos fundamentales y el análisis de proporcionalidad: la de quienes afirman la existencia de algún tipo de conexión (tesis de necesidad) y la de quienes niegan esta necesidad (tesis de contingencia). La tesis de necesidad se basa en la conocida distinción entre reglas y principios, se fundamenta en que las reglas son mandatos defınitivos que se aplican a través de la subsunción. Mientras, los principios son mandatos de optimización que se aplican a través de la ponderación. La ponderación requeriría obligatoriamente de una relación entre la teoría de los principios y el principio de proporcionalidad, por cuanto sería la proporcionalidad la que daría sentido a la optimización del principio.

De acuerdo con este autor, el principio de proporcionalidad está conformado por tres subprincipios: el de idoneidad y el de necesidad en referencia a las condiciones fácticas, cuyo objetivo es evitar el conflicto; el de proporcionalidad,

\footnotetext{
22 Bernal Puldo, Carlos. "La racionalidad de la ponderación", en Revista Española de Derecho Constitucional, No. 77, mayo-agosto de 2006, pp. 51-52.

${ }^{23}$ Carpio Marcos, Edgar. "La interpretación de los derechos fundamentales", en Derecho pucp. Revista de la Facultad de Derecho, No. 56, 2003, p. 506.

${ }^{24}$ Cfr. Bernal Puldo, Carlos. El principio de proporcionalidad y los derechos fundamentales. El principio de proporcionalidad como criterio para determinar el contenido de los derechos fundamentales vinculante para el legislador, Centro de Estudios Políticos y Constitucionales, Madrid, 2003, p. 126.

${ }^{25}$ Cfr. AleXY, Robert. "Los derechos fundamentales y el principio de proporcionalidad", en Revista Española de Derecho Constitucional, No. 91, enero-abril de 2011, pp. 11-29.
} 
en sentido estricto respecto a las posibilidades jurídicas, destinado a solucionar el conflicto. El principio de idoneidad excluiría la adopción de medios inidóneos que no sirvan para lograr la realización de un principio y, por el contrario, obstaculicen la realización de otro principio. Eliminarlo no iría en demérito de ningún principio; por el contrario, serviría para cumplir en mayor medida el principio que podía ser perjudicado. Más relevancia pareciera tener el principio de necesidad, por el cual, entre dos medios igualmente idóneos para cumplir un principio, cabe elegir el que menos lesione al otro principio. El fundamento de los dos principios, que acaba definiendo el concepto de optimización, es el óptimo de Pareto. Conforme a éste, un estado de cosas se consideraría óptimo cuando exista un equilibrio más allá del cual no es posible mejorar la posición de al menos un individuo sin que implique desmejorar la posición de algún otro. ${ }^{26}$

Pero una vez se establece que los principios son contrarios sería necesario apelar al principio de proporcionalidad en sentido estricto. Este principio se fundamenta en la "ley de la ponderación", determinada por el propio Alexy: cuanto mayor sea el grado de la no satisfacción de uno de los principios tanto mayor debe ser la importancia de la satisfacción del otro. Para realizar la ponderación sería necesario establecer el peso del principio en relación con el principio opuesto. El autor reconoce que las formulaciones que propone basada en cocientes sólo pueden habilitarse cuando se asignan cantidades numéricas en la escala infinitesimal entre 0 y 1 para graduar el peso, lo que imposibilitaba su uso en la argumentación jurídica. La solución requiere optar por valores cualitativos como leve o grave, o la conocida tríada leve, moderado y grave y la representación de estos valores a través de números que posibilitarían la acción de las fórmulas. No se negaría la discrecionalidad del legislador, pero se reduciría a los casos en que el peso concreto de cada principio fuera el mismo: en ese caso se permitiría tanto realizar la medida como omitirla. ${ }^{27}$

Como es sabido, aunque los fundamentos de la ponderación son ampliamente aceptados por un sector de la doctrina y de la jurisprudencia constitucional, varias son las críticas que se plantean a esta tesis. Resumidas por Bernal, serían de tesis que destacarian la irracionalidad de la ponderación a través de varios argumentos: a) la indeterminación conceptual; la ponderación sería una fórmula retórica o una técnica de poder carente de concepto claro y de una estructura jurídica determinada, por lo cual la ponderación no puede ser objetiva, y no puede ofrecer una sola respuesta correcta para los casos en que se aplica. b) La

\footnotetext{
${ }^{26}$ Cfr. Lopera Mesa, Gloria Patricia. "Los derechos fundamentales como mandatos de optimización", en Doxa. Cuadernos de Filosofía, No. 27, 2004, p. 213.

${ }^{27}$ Alexy, Robert. Op. cit., pp. 16-17.
} 
incomparabilidad y la inconmensurabilidad de los objetos que se ponderan; se intentan comparar principios que, por sus radicales diferencias, no son comparables, y no existe una organización jerárquica de los principios que se ponderan ni una medida común entre ellos. c) La imposibilidad de predecir los resultados de la ponderación; cada ponderación sería singular y sus características estarían determinadas por las características de los casos concretos, no por criterios generales, por lo cual sacrificaría la seguridad jurídica. d) La relación entre las objeciones de la ponderación, que compondría el fundamento de la crítica. ${ }^{28}$ En particular, para los defensores de la contingencia, cabe negar el carácter universal de la teoría de los principios; ésta debe limitarse a explicar concretamente las características de la colisión entre derechos fundamentales conformados como principios. Los derechos fundamentales no son principios en razón de su naturaleza, sino sólo cuando se positivan como tales. La conexión entre derechos y el principio de proporcionalidad vendría dada por su expresión en el derecho positivo. ${ }^{29}$ Es particularmente importante e influyente la conocida teoría habermasiana sobre la determinación de los derechos. Se sustenta en el marco de una democracia que habilita los espacios públicos para la elaboración de los derechos desde la autonomía de los individuos, miembros de una comunidad jurídica. ${ }^{30}$ En términos de Durango, para Habermas, el procedimiento democrático legitima el sistema y crea normas. Por medio de las acciones comunicativas, los individuos "son autores racionales de esas normas".

De este modo, el derecho adquiere su validez, al imponer su cumplimiento cuando se necesita para articular tejidos sociales complejos. Estos últimos precisan la validez de las normas, plenamente legalizadas en el Estado democrático de derecho. Las normas se fundan en el consenso de quienes se hallan sujetos a ellas: la justificación dada racionalmente sobre los acuerdos o desacuerdos sobre tales normas. ${ }^{31}$ El sistema de derechos es el que funda la necesidad del derecho objetivo y del poder político estatal como medio para la imposición y protección de esos derechos. ${ }^{32}$

Alexy contradice la contingencia, él entiende que los derechos fundamentales no son sólo derecho positivo. La positividad refleja sólo el lado real o

\footnotetext{
${ }^{28}$ Bernal Puldo, Carlos. "Los derechos fundamentales y la teoría de los principios. ¿Es la teoría de los principios la base para una teoría adecuada de los derechos fundamentales de la Constitución española?", en Doxa, Cuadernos de Filosofía del Derecho, No. 30, 2007, pp. 278-280.

${ }^{29}$ Alexy, Robert. "Los derechos..." op. cit. pp. 23-24.

${ }^{30} \mathrm{Cfr}$. Habermas, Jürgen. Facticidad y validez. Sobre el Derecho y el Estado democrático de Derecho en términos de teoría del discurso, Trotta, Madrid, 1998.

${ }^{31}$ Durango Álvarez, Gerardo. "El concepto de los derechos sociales en la teoria habermasiana: de la acción comunicativa a facticidad y validez", en Revista de Derecho, No. 33, 2010, p. 262.

${ }^{32}$ Cfr. Garcia Amado, Juan Antonio. "La filosofía del Derecho de Jürgen Habermas", en Doxa, No. 13, 1993, p. 245.
} 
fáctico de los derechos, pero éstos también cuentan con un lado ideal. El papel del constituyente sería únicamente positivar los derechos; esto es, convertir los derechos humanos en derechos positivos. Pero los derechos humanos son morales, universales, fundamentales, abstractos y prioritarios sobre los demás tipos de derechos. Por lo tanto, su existencia no depende de la voluntad del constituyente, y la dimensión ideal de los derechos humanos sobrevive con independencia de su positivación. Por otro lado, los derechos humanos cuentan con carácter abstracto, y por ello colisionan necesariamente con otros derechos humanos y con bienes colectivos; por ello requerirían de ponderación. ${ }^{33}$ Todo esto nos lleva al inacabable debate entre posiciones iusnaturalistas e iuspositivistas que yace en el fondo de las diferentes posiciones doctrinales.

El problema de la ordenación de los principios también es relevante en la crítica de Alexy. Como afirma Moreso, dado que los pesos abstractos de los principios son independientes de cualquier circunstancia concreta, deberíamos tener a nuestra disposición una asignación de peso abstracto para cada principio que establece un derecho constitucional; esto es, una escala de ordenación abstracta de los principios. Alexy se refiere, en general, a que el derecho a la vida debe tener mayor peso abstracto que la libertad general de actuar, pero esta intuición no puede suponer una escala de ordenación de todos los derechos constitucionales. Sin esa escala, en cada caso concreto deberá plantearse de nuevo la cuestión del peso abstracto de cada principio en liza. De hecho, ni siquiera está claro qué debería medir la supuesta escala abstracta de ordenación de los derechos constitucionales. ${ }^{34}$

Hoy en día sigue debatiéndose sobre la racionalidad o no racionalidad de la ponderación. En el fondo del debate se sitúa la impresión, casi certeza, de que ninguna fórmula lógica podrá ofrecer una única solución a cada caso concreto, y que cuando se trata de ponderar, permanece cierto margen de discrecionalidad del juez, incluso la doctrina más seria reconoce que este margen es relativamente amplio. ${ }^{35}$ Bernal, después de proponer un modelo más completo y complejo que la fórmula del peso, concluye:

debe reconocerse que la complejidad del modelo deriva de que la aplicación de los principios es en sí misma un procedimiento altamente complejo. Más allá de ello, es preciso enfatizar que la fórmula del peso

\footnotetext{
${ }^{33}$ Alexy, Robert. "Los derechos...", op. cit. pp. 24-25.

${ }^{34}$ MorESO, JUAN José. "Alexy y la aritmética de la ponderación", en Miguel Carbonell (Ed.), El principio de proporcionalidad y la interpretación constitucional, Ministerio de Justicia y Derechos Humanos del Ecuador, Quito, 2008, pp. 73-74.

${ }_{35}^{35}$ Véase Prieto Sanchis, Luis. "Neoconstitucionalismo y ponderación judicial", en Anuario de la Facultad de Derecho de la Universidad Autónoma de Madrid, No. 5, 2001, p. 222.
} 
no es un procedimiento algorítmico que pueda ofrecer a cada caso una única respuesta correcta. Por el contrario, este modelo de ponderación reconoce sus propios límites de racionalidad y abre al juez un margen de deliberación en el que su ideología y sus apreciaciones juegan el papel determinante. No obstante, este hecho no reduce la racionalidad ni la utilidad de la fórmula del peso. ${ }^{36}$

Parece querer decir que la racionalidad de la ponderación es relativa o propia, por ello no podríamos hablar de una racionalidad lógica e invariable sino de un particular concepto de racionalidad de la ponderación.

A pesar de todas las dudas respecto a la ponderación y a la proporcionalidad, los avances han sido muchos. Estamos hoy en día planteando fórmulas de solución de los conflictos entre derechos, basadas principalmente en la mayor protección efectiva posible del derecho en relación con la mayor protección efectiva posible del resto de derechos.

\section{El concepto de juez constitucional y el debate sobre la posible contradicción entre principios y reglas}

¿Cuál debe ser el papel del juez ordinario en la garantía de los derechos?, ¿y el del Tribunal Constitucional? Sería difícil plantear esta cuestión sin hacer referencia a las posturas neoconstitucionalistas. Éstas abogan por que el juez aplique los principios frente a las reglas, las cuales por formar parte de un paradigma anterior - legalista, en el sentido de positivista- podrían obstaculizar la aplicación directa de los principios.

Postulados como los de Alexy sustentan la corriente de pensamiento jurídico conocida como neoconstitucionalismo, el cual tuvo cierto auge en determinadas universidades europeas y latinoamericanas a partir de la década de los noventa del siglo xx. ${ }^{37}$ El neoconstitucionalismo parte de la confianza en el juez "hercúleo" al momento de ponderar y argumentar, por lo cual requiere 142 de la reflexión filosófico-jurídica sobre los valores (especialmente Dworkin), ${ }^{38}$ y de las teorías más sólidas sobre la ponderación, como la ya citada de Alexy.

\footnotetext{
${ }^{36}$ Bernal, CARlos. "La racionalidad...", op. cit. p. 73.

${ }^{37}$ Respecto a la concepción del neoconstitucionalismo como una teoría del derecho, sus rasgos identitarios, su recorrido teórico y su diferenciación con el nuevo constitucionalismo, cfr. Viciano PASTOR, Roberto y Martinez Dalmau, Rubén. "La Constitución democrática, entre el neoconstitucionalismo y el nuevo constitucionalismo", en El Otro Derecho, No. 48, 2013, p. 66.

${ }^{38}$ Entre todas, la obra angular en el debate con Hart sobre cómo decide el juez: DworkIN, RonaLD. Los derechos en serio, Ariel, Barcelona, 2002. Sobre el debate, cfr. Rodriguez, César. La decisión judicial. El debate Hart-Dworkin. Siglo del Hombre, Bogotá, 1997; Martínez Dalmau, Rubén. "La interpretación...", op. cit., p. 440.
} 
Se trataría, afirman algunos de los defensores del neoconstitucionalismo, ${ }^{39}$ de sustituir el principio de legalidad -fundamento del positivismo- por el de proporcionalidad - materia básica en el neoconstitucionalismo- en aquellos casos en que se encuentren en contradicción. Afirma Ávila que:

el principio de proporcionalidad [...] se contrapone a la legalidad cuando en el sistema jurídico se presentan antinomias entre la ley y la Constitución, y permite al juez sospechar de la ley y hasta inaplicarla [...]. En la realidad de nuestros sistemas jurídicos, lamentablemente, los dos principios, en la mayoría de los casos, se encuentran en contradicción, lo cual hace que el rol de los jueces sea mayor. ${ }^{40}$

¿Qué significa que el rol de los jueces sea mayor para esta postura neoconstitucionalista? Que el juez ordinario se involucre en el problema concreto de hacer justicia y deje de aplicar una norma cuando, a través de la argumentación y de la ponderación, entienda que la norma es inconstitucional. Esto es, el clásico método de la judicial review norteamericana vigente desde 1803. El autor lo explica con claridad:

El juez tiene en sus manos casos concretos de personas reales y en esos casos existen acontecimientos problemáticos: las víctimas y los victimarios tienen derechos en un conflicto penal. En esos casos, debe comprender el sentido del hecho con el derecho, la conexión de la acción con la limitación, no puede ser indiferente al resultado de las acciones, debe analizar la proporcionalidad en el contexto, valorar, [...] aplicar los principios si las reglas generan un resultado injusto y resolver adecuadamente. ${ }^{41}$

Ahora bien; la capacidad del juez ordinario de determinar que una regla no puede ser aplicada porque es contraria a la Constitución ¿soluciona realmente el conflicto del derecho o incorpora más gravedad? Para analizar este problema,

\footnotetext{
${ }^{39}$ Cabe tomar en cuenta que las posturas respecto al neoconstitucionalismo son, en su origen, plurales y no convergen en muchos de sus aspectos; posteriormente, se intenta su homogeneización. Respecto al origen diverso de las teorias neoconstitucionalistas, cfr. CARBonell, Miguel. Neoconstitucionalismo(s), Trotta, Madrid, 2003; sobre los ensayos para su canonización, cfr. Carbonell, Miguel y Garcia Jaramillo, Leonardo. El canon neoconstitucional, Universidad Externado de Colombia, Bogotá, 2010.

${ }^{40}$ Ávila Santamaria, Ramiro. "El principio de legalidad vs. el principio de proporcionalidad. Reflexiones sobre la constitucionalidad de las leyes penales y el rol de los parlamentos y los jueces", en Miguel Carbonell (Ed.), El principio de proporcionalidad..., op. cit., p. 308.

${ }^{41}$ Ibid. pp. 329-330.
} 
debemos regresar a la ya mencionada diferenciación entre interpretación legal e interpretación constitucional, y al rol del juez ordinario en los sistemas constitucionalizados.

Aunque con la solidez que le caracteriza, Guastini niega la diferencia entre interpretación legal e interpretación constitucional, calificándose él mismo de escéptico realista. ${ }^{42}$ Lo cierto es que esta diferenciación es necesaria en nuestros sistemas de gobierno, entre el papel del juez ordinario y el del juez constitucional. El papel del juez ordinario, tal y como lo plantean algunos teóricos del neoconstitucionalismo que hunden sus raíces en la propuesta dworkiniana, nos llevaría a una Constitución conformada en su parte dogmática casi exclusivamente por principios de aplicación directa del juez que otorga justicia en el caso concreto. La consecuencia sería concebir al juez ordinario como un aplicador de los principios con la discrecionalidad consustancial a esta función en la búsqueda de la justicia concreta, dentro del marco de la razonabilidad de la ponderación y reducir a su mínima expresión la intervención del legislador, de quien se desconfía desde el prisma neoconstitucionalista. ${ }^{43}$ Se trata de una doctrina que no sólo huye del problema de la legitimidad democrática, sino que conscientemente la rebate por los miedos hacia la acción de las mayorías. Prieto Sanchís no lo podría haber resumido mejor:

[el neoconstitucionalismo] recoge la idea de garantía jurisdiccional y una correlativa desconfianza ante el legislador; cabe decir que la noción de poder constituyente propia del neoconstitucionalismo es más liberal que democrática, de manera que se traduce en la existencia de límites frente a las decisiones de la mayoría, no en el apoderamiento de esa mayoría a fin de que quede siempre abierto el ejercicio de la soberanía popular. ${ }^{44}$

\footnotetext{
${ }^{42}$ Con autores como Tarello, Troper o Chiassoni. Cfr. GuastinI, RiCCARDo. Op. cit. p. 41-42.

${ }^{43}$ Como se ha afirmado en otra sede, "uno de los grandes problemas del neoconstitucionalismo es que no diferencia sustantivamente entre la función de los jueces que realizan el control concentrado de constitucionalidad -los tribunales constitucionales - y la justicia ordinaria, cuya interpretación de la Constitución viene premodulada por la realizada por los intérpretes auténticos (los mencionados tribunales constitucionales). En la confusión, propia del neoconstitucionalismo, entre sistema difuso y sistema concentrado, los jueces ordinarios acaban asumiendo la función de limitador a la libertad del legislador, lo que en última instancia significa la sustitución del legislador. Esta sustitución puede corresponder al juez que realiza el control de constitucionalidad, por el carácter político de su función como legislador negativo; pero no asi al juez ordinario, que no está legitimado democráticamente para desarrollar una función política. El gran problema de la libertad del juez ordinario a la hora de aplicar la Constitución libremente es que no cuenta con la legitimidad democrática -ni la correspondiente legitimidad constitucional- para declararse por él mismo intérprete político de la Constitución". Viciano Pastor, Roberto y Martinez Dalmau, Rubén. Op. cit. p. 71.

${ }^{44}$ Prieto Sanchis, Luis. Op. cit. p. 204.
} 
Menguaría, por lo tanto, el principio de legalidad y se usaría la voluntad constituyente para legitimar la función del juez activista.

Pero seguramente esta no es una solución acorde con el concepto material del Estado constitucional. La materialidad del Estado constitucional se caracteriza por la aplicación de la voluntad del poder constituyente democrático. Por lo tanto, todos los órganos públicos deben estar comprometidos en el desarrollo del principio democrático, el cual se manifiesta en la voluntad del poder constituyente expresada en la Constitución. La aplicación de la Constitución en todo caso requiere de reglas que garanticen la realidad material del texto constitucional. ${ }^{45}$

La justicia en el Estado constitucional se traduce precisamente en la garantía de la Constitución. Exige tanto una interpretación integradora -principios y reglas- como órganos constitucionales destinados al cumplimiento de la Constitución, en forma y materia, porque no le corresponde al juez ordinario estar solo frente al objetivo del cumplimiento de la Constitución. Se trata de lo que Ferrajoli denomina garantismo: "El paradigma del Estado constitucional de derecho -o sea, el modelo garantista- no es otra cosa que esta doble sujeción del derecho al derecho, que afecta a ambas dimensiones de todo fenómeno normativo: la vigencia y la validez, la forma y la sustancia, los signos y los significados, la legitimación formal y la legitimación sustancial" ${ }^{46}$

Desde la óptica neoconstitucionalista podría aducirse que restringir el juez ordinario al cumplimiento de principios y reglas, tanto de la Constitución como de la ley, sería mantenerse en el paradigma positivista y desaprovechar el momento histórico para convertir al juez legal en un juez constitucional. Nada más lejos de la realidad. La Constitución del Estado constitucional requiere que todos los jueces sean jueces constitucionales, en sentido sustantivo; esto es, que garanticen la aplicación de la Constitución. En términos de Ferrajoli:

la sujeción del juez a la ley ya no es, como en el viejo paradigma positivista, sujeción a la letra de la ley, cualquiera que fuere su significado, sino sujeción a la ley en cuanto válida, es decir, coherente con la

\footnotetext{
${ }^{45}$ De hecho, una parte de la doctrina sigue insistiendo en la arbitrariedad del balancing y en la necesidad de seguir confiando en reglas frente a principios por su capacidad para proteger los derechos. Para Tschentscher, por ejemplo, el balancing es un peligro para la libertad individual, y hay muy buenas razones en la mayor parte de los derechos fundamentales para confiar en un sistema basado en reglas más que en un sistema basado en principios. Además, la flexibilidad en los sistemas legales no necesitaría de los principios, sino que también podria conseguirse por reglas convenientemente diseñadas. Cfr. TsCHEnTSCHER, Axel. "Interpreting Fundamental Rights. Freedom versus Optimization", en Hermann Pünderr y Christian Waldhoff (Eds.), Debates in German Public Law, Hart Publishing, Oxford, 2014, p. 43.

${ }^{46}$ Ferrajol, Luigi. Derechos y garantías. La ley del más débil, Trotta, Madrid, 2004, p. 22.
} 
Constitución. Y en el modelo constitucional garantista la validez ya no es un dogma asociado a la mera existencia formal de la ley, sino una cualidad contingente de la misma, ligada a la coherencia de sus significados con la Constitución [...]. De ello se sigue que la interpretación judicial de la ley es también siempre un juicio sobre la ley misma, que corresponde al juez junto con la responsabilidad de elegir los únicos significados válidos, o sea, compatibles con las normas constitucionales sustanciales y con los derechos fundamentales establecidos por las mismas. ${ }^{47}$

Ahora bien, como el objeto es el cumplimiento de la Constitución, el juez ordinario debe cumplir su rol en el marco integrador del resto de órganos públicos y respetando la determinación de sus competencias. El juez ordinario es juez materialmente constitucional porque colabora garantizando el cumplimiento de la Constitución. Por ello, su papel en el entramado público es la aplicación directa tanto de los principios como de las reglas; tanto constitucionales como legales, de acuerdo con las decisiones del Tribunal constitucional. Para ello, es necesario reducir la discrecionalidad que, como hemos referido, es inherente a la ponderación. ${ }^{48} \mathrm{El} \mathrm{juez} \mathrm{debe} \mathrm{interpretar} \mathrm{contando} \mathrm{siempre} \mathrm{con}$ la jurisprudencia del Tribunal constitucional, órgano competente para decidir en el marco de la discrecionalidad de la ponderación. Cuando el juez ordinario interpreta la Constitución, esa interpretación debe poder ser avalada por el Tribunal constitucional (juez constitucional en sentido orgánico). Con excepción dentro del funcionamiento de los órganos públicos en un Estado constitucional, la decisión final sobre si una regla de configuración legal está de acuerdo o no con la Constitución sólo puede corresponder al Tribunal Constitucional. El cual es el órgano competente, con capacidad para argumentar y decidir en el ámbito de discrecionalidad propio de la ponderación. De lo contrario, convertiriamos al juez ordinario en un juez político.

En el sentido expuesto, la duda kelseniana nos sigue siendo útil: cuando el juez ordinario duda sobre la aplicación de una regla infraconstitucional debe plantear esta duda al Tribunal constitucional. ${ }^{49}$ De esa forma, coadyuva al

\footnotetext{
${ }^{47}$ Ibid. p. 26.

${ }^{48}$ En términos de Prieto Sanchis, los jueces no comparten "una moral objetiva y conocida, ni son coherentes en sus decisiones, ni construyen un sistema consistente de derecho y moral para solucionar los casos, ni argumentan siempre racionalmente; y ello tal vez se agrave en el caso de la ponderación, donde las 'circunstancias del caso' que han de ser tomadas en consideración constituyen una variable de difícil determinación, y donde el establecimiento de una jerarquia móvil descansa irremediablemente en un juicio de valor". El autor, a continuación, hace un esfuerzo por matizar las críticas provenientes desde el subjetivismo. Prieto Sanchis, Luis. Op. cit., pp. 222-223.

${ }^{49}$ De hecho, esta es la norma general en los sistemas de control concentrado de la constitucionalidad: el acceso
} 
cumplimiento de la Constitución, y se convierte materialmente en juez constitucional. Siguiendo también a Ferrajoli:

esto y no otra cosa [...] es lo que entendíamos [...] con la expresión 'jurisprudencia alternativa' [...]: interpretación de la ley conforme a la Constitución y, cuando el contraste resulta insanable, deber del juez de cuestionar la validez constitucional; y, por tanto, nunca sujeción a la ley de tipo acrítico e incondicionado, sino sujeción ante todo a la Constitución, que impone al juez la crítica de las leyes inválidas a través de su reinterpretación en sentido constitucional y la denuncia de su inconstitucionalidad. ${ }^{50}$

Tanto la composición política del Tribunal Constitucional como su ámbito orgánico competencial imponen que éste reúna las condiciones para ser el máximo intérprete constitucional. Asimismo, aplicar los criterios de razonabilidad en la interpretación de la Constitución y de los derechos con estructura de principios en particular. ${ }^{51}$ Confiar en manos del juez ordinario la garantía de la Constitución, a través de la aplicación de la Constitución y las leyes constitucionales. Vigilar la constitucionalidad del ordenamiento jurídico a través de la denuncia al Tribunal Constitucional de las leyes potencialmente inconstitucionales.

Es ese el significado que debería cobrar el activismo judicial, aquello que Saavedra denomina el uso democrático del derecho, ${ }^{52}$ y no la arrogación de funciones que por su naturaleza no le corresponden, ni deben corresponder, a los jueces ordinarios.

\footnotetext{
al Tribunal constitucional por parte del juez ordinario a través de las cuestiones de constitucionalidad. Cuestión diferente es la de los sistemas denominados mixtos: al mantener la capacidad de los jueces ordinarios para dejar de aplicar una regla que consideren inconstitucional, cuentan con cierto grado de inestabilidad que posiblemente derive, de facto y quizás de iure, hacia un sistema concentrado puro. Con todo, el sistema mixto entraria dentro del paradigma de constitucionalidad expuesto siempre que existan los mecanismos, como la tutela contra sentencia, que faciliten que la decisión final corresponda por decisión expresa o tácita al Tribunal constitucional.

${ }^{50}$ FerRAJol, LUIGI. Op. cit. p. 26.

${ }^{51}$ Al respecto, cfr. Galán JuÁrez, Mercedes. "La interpretación de los derechos fundamentales por parte del Tribunal Constitucional: una argumentación en términos de razonabilidad", en Isegoría, No. 35, julio-diciembre de 2006, p. 50.

${ }^{52}$ Saavedra se inscribe entre quienes abordan la necesidad de una interpretación democrática del derecho realizada por los jueces desde la perspectiva crítica. "El único uso del derecho permisible para los jueces en un Estado democrático es precisamente el uso democrático del derecho. No solamente es el único uso permisible, sino que al mismo tiempo es el uso obligado del derecho. Utilizar democráticamente el derecho significa ahondar en el sentido de la Constitución y extraer de ella todas sus consecuencias [...]. El uso del derecho equivale a una interpretación democrática del mismo. La interpretación democrática del derecho tiene un carácter crítico". Cfr. SAAVEDRA, Modesto. "Interpretación judicial del Derecho y Democracia", en Travesías. Política, Cultura y Sociedad en Iberoamérica, No. 1, julio-diciembre de 1996, pp. 243-244.
} 


\section{Derechos constitucionales, derecho internacional y derecho de la integración}

Finalmente, ¿qué implica la interpretación de los derechos en el marco de los procesos de integración y cuál es su relación con la supremacía constitucional? Una primera respuesta necesita revisar el papel del derecho internacional: en general, en la interpretación constitucional y, en particular, respecto a los derechos. Es frecuente en las Constituciones encontrar cláusulas interpretativas de apertura; aquellas que realizan un llamamiento a tratados internacionales y al derecho de la integración como criterios de interpretación para la aplicación de las propias cláusulas internacionales. Las Constituciones del constitucionalismo social aparecidas en Europa después de la Segunda Guerra Mundial innovaron esta categoría de cláusulas, como reacción a los sucesos bélicos acontecidos durante la primera mitad del siglo xx, y en búsqueda de mecanismos de protección internacional de los derechos. Esto no sólo se hizo a través de cortes internacionales especializadas en derechos humanos, como el Tribunal de Estrasburgo, sino también a través de la penetración de los compromisos internacionales en el orden interno, como mecanismo preventivo y garante de los derechos.

Son varios los casos en los que encontramos cláusulas de apertura respecto a la aplicación e interpretación de los derechos. Por ejemplo, el artículo 10.2 de la Constitución española de 1978 determina que "las normas relativas a los derechos fundamentales y a las libertades que la Constitución reconoce se interpretarán de conformidad con la Declaración Universal de Derechos Humanos y los tratados y acuerdos internacionales sobre las mismas materias ratificados por España”. Se trata de un argumento comparativo que conecta el orden constitucional interno con el orden constitucional internacional. Recordemos que la legitimidad del derecho internacional en el marco interno se obtiene a través de la Constitución, norma suprema del ordenamiento jurídico. Como afirma Galán, es una manifestación del criterio sistemático, toda vez que los

148 tratados internacionales son en definitiva derecho interno. ${ }^{53}$ El intérprete no puede desconocer, por lo tanto, la función del derecho internacional como parámetro de interpretación. ${ }^{54}$

\footnotetext{
${ }^{53}$ Galán Juárez, Mercedez. Op. cit. p. 50

${ }^{54}$ En términos del Tribunal Constitucional español, el artículo 10.2 de la Constitución Española "no da rango constitucional a los derechos y libertades internacionalmente proclamados en cuanto no estén también consagrados por nuestra propia Constitución, pero obliga a interpretar los correspondientes preceptos de ésta de acuerdo con el contenido de dichos Tratados o Convenios, de modo que en la práctica este contenido se convierte en cierto modo en el contenido constitucionalmente declarado de los derechos y libertades que enuncia el capítulo segundo del
} 
Una problemática particular corresponde a la aplicación del derecho de la integración. Por ejemplo, en el marco de la Unión Europea, estamos refiriéndonos a un tipo de derecho que no encaja en los cánones habituales del derecho internacional. Las cláusulas de apertura generales, no exclusivamente las de interpretación de los derechos, reconfiguran el ámbito competencial interno a través de la supranacionalidad, introduciendo por autoridad de la Constitución la vigencia de un derecho válido por sí mismo, si es aprobado de acuerdo con lo estipulado en los tratados originarios de integración..$^{55}$

La cuestión cobró mayor interés a partir de la entrada en vigor del Tratado de Lisboa, de 2007, tras el fracaso del "Tratado constitucional" europeo. En su artículo sexto, el Tratado de Lisboa otorgó a la Carta de Derechos Fundamentales de la Unión Europea de 2000 (Carta de derechos de Niza) el mismo valor jurídico que los tratados. Ello implicó una gran novedad en materia de integración supranacional e interpretación de derechos: la incorporación de una carta de derechos, de naturaleza comunitaria, mucho más amplia que las conocidas como libertades comunitarias ${ }^{56}$ que se consagraron con la entrada en vigencia del Tratado de Maastricht (Tratado de la Unión Europea, 1992) y su relación con las Constituciones de los Estados miembro. En particular, cuando la Carta de derechos fundamentales cuenta con sus propios artículos sobre interpretación, e incorpora garantías para la interpretación de los derechos que han fundamentado la construcción teórica sobre la interpretación, desde la segunda mitad del siglo xx: el respeto al contenido esencial, y principio de proporcionalidad.$^{57}$ Además, aparecen en una misma cláusula, a diferencia de lo que es común en derecho constitucional comparado.

Como afirma Rolla, la cláusula del respeto del contenido esencial de los derechos no representa un criterio autónomo, sino uno de los ámbitos de valoración necesarios para aplicar el principio de proporcionalidad, lo cual favorece a las posiciones doctrinales que consideran la garantía del contenido esencial como un elemento complementario a los principios de razonabilidad y proporcionalidad. ${ }^{58}$

título I de nuestra Constitución". (sтc 36/1991, de 14 de febrero, Fundamento Jurídico 5).

${ }^{55}$ Siguiendo con el ejemplo español y su relación con el proceso europeo de integración, Aroz advierte sobre la circunstancia de que "los tratados constitutivos de las comunidades europeas y los tratados posteriormente celebrados no encajan exactamente en la categoría 'tratado internacional sobre derechos humanos' del artículo 10.2 Código Español, en cuanto que representan un derecho supranacional". Cfr. Aroz Santisteban, Xavier. "La relevancia del Derecho de la Unión Europea para la interpretación de los derechos fundamentales constitucionales", en Revista Española de Derecho Constitucional, No. 74, mayo-agosto de 2005, pp. 64-65.

${ }^{56}$ Libre circulación de mercancias, personas, servicios y capitales.

${ }^{57}$ Cfr. Escobar Roca, Guillermo. "Elementos de teoría de los derechos fundamentales de la Unión Europea", en Revista Catalana de Dret Públic, No. 37, 2008, p. 408.

${ }^{58}$ Rolla, Giancarlo. "Técnicas de codificación y cláusulas de interpretación de los derechos fundamentales. Algunas 
Ahora bien, nada de lo dicho es incompatible, ni puede serlo, con la supremacía de la Constitución. La Constitución democrática es abierta en los casos en que la apertura hacia el derecho internacional o el derecho de la integración beneficien la vigencia de los derechos; pero actúa como freno $-\mathrm{y}$ por lo tanto es cerrada- cuando la incorporación del derecho internacional o del derecho de la integración vulnera alguno de los derechos determinados en la propia Constitución, porque este es el verdadero sentido de supremacía constitucional. Es fundamental para ello diferenciar entre jerarquía (supremacía de la Constitución) y aplicación (del derecho internacional o del derecho de la integración, que puede ser preferente a la constitucional).

Como se ha dicho en otra sede, el derecho de la integración no podría menoscabar los derechos constitucionales, por cuanto estos gozan de una posición jerárquica superior, de acuerdo con los límites y condiciones que recoge la propia Constitución. La legitimidad de la Constitución democrática como norma suprema del ordenamiento jurídico la dota del mayor rango jerárquico en dicho ordenamiento (supremacía). Por lo tanto, cualquier aplicación de un tratado internacional que menoscabara un derecho constitucional sería materialmente inconstitucional. El ordenamiento jurídico internacional podría, en todo caso, mejorar la situación de los derechos constitucionales, porque se aplicarían con preferencia a la Constitución en virtud de las normas de apertura o se ayudaría a la más conveniente aplicación de la Constitución. ${ }^{59}$ Corresponde tanto a los tribunales ordinarios como al Tribunal Constitucional velar por la supremacía de la Constitución en el sentido expuesto, como norma de apertura así como norma de cierre.

\section{Conclusiones}

La interpretación de la Constitución conlleva el esfuerzo necesario para que se garantice la máxima aplicación de los derechos. Pero el significado y la garantía de los derechos no pueden consistir en una decisión unilateral del 150 juez. La Constitución democrática es fruto de una voluntad constituyente que ha determinado cómo se configuran constitucionalmente los derechos y cuáles son sus mecanismos de aplicabilidad. El juez constitucional, intérprete superior de la Constitución, debe tomar en cuenta esta voluntad como criterio

consideraciones a propósito de la Carta de Derechos Fundamentales de la Unión Europea", en Revista de Derecho Constitucional Europeo, No. 4, julio-diciembre de 2005, p. 106.

${ }^{59}$ Cfr. Tremolada Álvarez, Eric y Martinez Dalmau, Rubén. "Jerarquía constitucional y aplicación preferente del derecho de la Integración. Elementos para la solución del posible conflicto entre derechos e integración", en Vniversitas, No. 128, enero-junio de 2014, p. 407. 
de legitimidad de su decisión, y entender que la interpretación de acuerdo con otros parámetros puede suponer en última instancia la falta de legitimidad de la interpretación realizada.

La doctrina mayoritaria, en relación con el conflicto de derechos formulados como principios, apoya el método de la ponderación. Desde diferentes posiciones, la ponderación de derechos, vinculada con las reflexiones sobre el núcleo esencial, entiende que la aplicación de los derechos en caso de conflicto debe realizarse en su máximo potencial, sin desvirtuar el derecho que suscita el conflicto.

Aunque la ponderación se revista de elementos técnicos, no deja de tener un componente de decisión importante. Cabe seguir trabajando sobre las condiciones y los límites de la ponderación, tomando en cuenta las críticas de un sector nada desdeñable de la doctrina. Sector que, no obstante, ha propuesto pocas alternativas a la ponderación para solucionar los conflictos de derechos.

La existencia de una Constitución democrática supone la diferenciación entre voluntad constituyente y voluntad constituida; por tanto, la búsqueda de mecanismos constitucionales comprometidos en la garantía de la Constitución en general, y de los derechos protegidos en ella en particular. Para ello, es necesaria una lectura protectora y fortalecedora de la Constitución, la cual realiza el tribunal constitucional. La interpretación vinculante de la Constitución es la principal función de los tribunales constitucionales. Se diferencia sustancialmente de la interpretación realizada por el juez ordinario, obligado por la jurisprudencia constitucional.

A pesar de las reflexiones al respecto por parte de cierto sector de la justicia, la diferenciación entre interpretación por el juez constitucional e interpretación por el juez ordinario sigue más vigente que nunca en el constitucionalismo democrático.

Por último, la posibilidad de que en el marco del derecho internacional o del derecho de integración existan normas que beneficien la aplicación de los derechos internacionalmente normados sobre los constitucionalmente determinados no es un problema de jerarquía. La supremacía de la Constitución, máxima jerarquía, no puede estar en discusión en una Constitución democrática, porque la legitimidad proviene del ordenamiento jurídico. Proviene de su carácter democrático. La aplicación de una norma sobre la propia Constitución debe ser admitida por la Constitución, por lo cual se garantiza la máxima jerarquía constitucional. Lo contrario sería quebrar el fundamento democrático de la norma internacional. 